\title{
Lived Experience with Cirrhosis of Liver Patient at a University Hospital: A Qualitative Study
}

\author{
Bushra E. Jannat ${ }^{*}$, Mohammad Nurul Anowar ${ }^{2 *}$, Shariful Islam², Dipali Rani Mallick ${ }^{3}$ \\ ${ }^{1}$ Bangabandhu Sheikh Mujib Medical University, Dhaka, Bangladesh \\ ${ }^{2}$ Faculty of Adult and Elderly Health Nursing, National Institute of Advanced Nursing Education and Research (NIANER), \\ Dhaka, Bangladesh \\ ${ }^{3}$ Faculty of Women's Health and Midwifery Nursing, National Institute of Advanced Nursing Education and Research (NIANER), \\ Dhaka, Bangladesh \\ Email: ^bushraejannat@gmail.com, ^mn.anowar@yahoo.com
}

How to cite this paper: Jannat, B.E., Anowar, M.N., Islam, S. and Mallick, D.R. (2020) Lived Experience with Cirrhosis of Liver Patient at a University Hospital: A Qualitative Study. Open Journal of Gastroenterology, 10, 266-280.

https://doi.org/10.4236/ojgas.2020.1010026

Received: September 1, 2020

Accepted: October 19, 2020

Published: October 22, 2020

Copyright ( 2020 by author(s) and Scientific Research Publishing Inc. This work is licensed under the Creative Commons Attribution International License (CC BY 4.0).

http://creativecommons.org/licenses/by/4.0/

\section{(c) (i) Open Access}

\begin{abstract}
Introduction: Patients' physical, psychosocial, economical, spiritual and daily activities as well as quality of life are mostly affected by the cirrhosis of liver. It is an advanced stage of liver fibrosis that mostly caused by hepatitis $\mathrm{B}$ and hepatitis $\mathrm{C}$, and alcoholism. Objective: This study is intended to explore the lived experience of the patient's with cirrhosis of liver patients. Methodology: A Phenomenological study design was used as a research methodology to elicit in-depth understanding of lived experience of the hospitalized adult cirrhosis of liver patients at Bangabandhu Sheikh Mujib Medical University, Dhaka, Bangladesh. Twenty patients with cirrhosis of liver were purposively interviewed using guidelines until data were saturated. Recorded voice was checked by participants to establish trustworthiness. Interviews were recorded, transcribed verbatim and translated. Content analysis was used to explore the structure of meaning of the lived experienced cirrhosis of liver patients. Results: The average age of the cirrhosis of liver patients was $43.85( \pm 15.06)$ and most of them were male, Muslim and married. The average duration of suffering from this disease was 2.07 year \pm 3.95 . The lived experiences of cirrhosis of liver patients emerged at five themes: uncertainty about disease and its causes; feeling worse; living in physical impairment and economical crisis; coping with disease and self-actualization about prevention of cirrhosis of liver. Conclusion: People with cirrhosis of liver have unpredictable sufferings. The study findings would help the nurses to realize the patient's condition for providing proper nursing care and prevent associate complications. It may also assist in conducting further research.
\end{abstract}




\section{Keywords}

Cirrhosis of Liver, Lived Experience, Liver Cirrhosis Patient

\section{Introduction}

\subsection{Background}

Cirrhosis of liver is an irreversible and a fatal disease arising from different chronic liver disorders and it is an advanced stage of liver fibrosis [1] [2] [3]. It hampers patients' daily life as well as health related quality of life [4] [5] [6] that mostly depend on nursing management [4], in which damaged tissues are replaced by collagen layers and lead to deficiency of the liver cell function [1] [2] [3]. Decompensated cirrhosis may lead to hepatocellular carcinoma [3].

Cirrhosis of liver is a common health problem around the world. An estimated prevalence of cirrhosis is $69 \%$ of adults in the United States [7]. Study from Australia reported that cirrhosis is the $6^{\text {th }}$ most prevalent cancer and $2^{\text {nd }}$ most leading cause of cancer related death globally [8]. In the Asia-Pacific region $54.3 \%$ death occurred due to cirrhosis of liver in 2015 globally [9]. Hepatitis was estimated as the $2^{\text {nd }}$ the prevalence of hepatitis in Pakistan was in $2^{\text {nd }}$ position among other diseases [10]. One of the study in Bangladesh showed that majority of cirrhosis patients were (68\%) males and $(31.82 \%)$ were females [2] and $50 \%$ of the patients were in the age group of 31 - 50 years [11]. In Bangladesh HCC being the third most common cause of cancer deaths, it is just behind cancer of the stomach [12] [13].

The actual causes of cirrhosis of liver can't be identified yet [14]. However, most of the studies reported that chronic hepatitis $B$ and hepatitis $C$ infection are the causes of more than half of all cases of liver cirrhosis [1] [2] [4] [15]-[20]. The other suspected common causes of cirrhosis of liver are consuming alcohol [2] [17] [21] [22] [23] hepatitis A, D, and E rarely by cytomegalovirus (CMV), Epstein-Barr virus (EBV) and fungal infections [15].

Some studies revealed that body mass index (BMI), non-alcoholic fatty liver disease and diabetes mellitus [7] [17] have been considered as the risk factors of cirrhosis of liver. Other risk factors are hyperlipidemia, other autoimmune disease, family history of liver disease, sexual orientation, intravenous drug abuse, blood transfusion, and significant alcohol use even in the past [7].

Clinical presentation is often asymptomatic. Particularly in the primary care setting detection of cirrhosis is often missed at its earliest stages [7]. The most physical and psychological symptoms include fatigue, abdominal discomfort, muscle cramps, irregular sleep pattern, jaundice, pruritis, gastrointestinal symptoms, impaired mobility breathlessness, change of body image, pitting edema, stress, anxiety and depression [17]. Sometimes symptoms related to complications of cirrhosis can appear without much warning [16]. Ascites, hepato-renal syndrome, severe portal hypertension, bacterial peritonitis and, hepatic ence- 
phalopathy are important complications of advanced cirrhosis [1].

As the lived experience, higher degree self-reported stress and anxiety about liver health amplified among severe fibrosis patient [24]. Majority of the subjects reported with their disease experience about physical and psychosocial problems that affect their daily and social activities [25]. But they could not tell why they didn't feel well, the causes, and symptoms to explain to cirrhosis of liver disease. Though they experienced about physical problem (such as ascites, gastrointestinal bleeding), including psychological burden [26].

In Bangladesh, there were some quantative descriptive studies available focusing on distribution of liver disease, causes of cirrhosis of liver, management of HCC, elimination of Hepatitis viruses [2] [11] [12] [27]. There were very scanty of existing study focusing on lived experience of cirrhosis of liver including Bangladesh. However, lived experience or qualitative research strategies are flexible; it aims to obtain comprehensive understanding of context from the participants. Research question may be modified until the actual expected result. This lived experience studies is very important for nursing because to the control and recovery from this disease most of the time depends on nursing management [4]. Therefore, researcher was interested to conduct this study with the aim of exploring the lived experience and cirrhosis of liver patient at a University hospital in Bangladesh.

\subsection{Objective}

To explore how patient with cirrhosis of liver experience their daily life during critical illness.

\section{Methodology}

\subsection{Study Design}

A Phenomenological study was employed to explore the experience of liver cirrhosis patient.

\subsection{Study Participants}

The study participants were the hospitalized adult patients with Cirrhosis of Liver in the BSMMU, Dhaka, Bangladesh. Twenty cirrhosis of liver patients were purposively selected for data collection until it's saturated using some inclusion criteria such as:

Medically diagnosed patients with cirrhosis of liver were willing to participate in the study, cognitively well and had no severe.

\subsection{Instruments}

Data were collected using Socio-demographic questionnaire and Data Generating Interview Guidelines. The interview guideline was developed through literature review and experience of healthcare providers. It consists of open ended questions to explore the feelings, thoughts, impact and need of cirrhosis of liver 
patients. The interview guideline was pilot tested with two patients with cirrhosis of liver. The interview was conducted in conversational language. Data Generating Interview Guidelines are as follows:

1) Could you tell me, what types of disease have you been suffering?

2) What you know about this disease?

3) What do you think about the causes of this disease?

4) Could you tell me about your physical problem due to cirrhosis of liver?

5) How this problem is affecting on your daily activities, dietary behaviors mental condition, socio-economic condition and overall health?

6) Could you tell me about your daily life style, spiritual and sleeping pattern?

7) What types of medication are you taking now for this disease purpose?

8) Any side effects have you been experiencing/facing due to intake of medication?

9) What is your suggestion about the preventing of this disease for others?

10) Anything more that you would like to share with me?

\subsection{Data Collection}

Data were collected from the month of December 2018 to January 2019. Prior to data collection, the proposal was approved by the Institutional Review Board (IRB) of National Institute of Advanced Nursing Education and Research (NIANER) and Bangabandhu Sheikh Mujib Medical University (BSMMU), Dhaka, Bangladesh and IRB No.Exp.NIA-S-2018-12. Permission was obtained from the hospital authority and informed consent from the patient was taken before collecting data. Audio-tape recorder also was used. All patients were ensured that their participation would be voluntary and recorded documents were heard and delivered to the participant to ensure trustworthiness. Data were collected until the completing of data saturation. The subjects' confidentiality and anonymity were strictly maintained with code numbers. Each interview duration was around $1-1.20$ hours. Subjects had the rights to withdraw them from the study at any time without any reason. Subjects were informed that the findings of the study would be submitted to scientific journal for publication and presented at conferences. All necessary information were collected from the subjects were kept confidential and destroyed after completion of the study.

\subsection{Data Analysis}

Data analysis process preserved the uniqueness of each participant's lived experience in the purpose of data analysis in a phenomenological study [28]. Interviews were transcribed verbatim by the researcher in Bengali language and audio tape recorder listening repeatedly to verify. Then the transcribed data were translated into English language and developed codding categories and also developed major themes based on the cirrhosis of liver patients' experience. In this study, content analysis was used to explore the structure of meaning of the lived 
experienced of cirrhosis patient. This was manual exploration of the primary themes and structure of the lived experience.

\section{Results}

This chapter described the Socio-demographic characteristics of cirrhosis of liver patients that was analyzed by using frequencies, percentage, mean and standard deviation, and also described cirrhosis of liver patients' experiences using content analysis that was emerged at 5 themes. These are follows: uncertainty about disease and its causes, feeling worse, living in physical impairment and economic crisis, coping with disease and self-actualization about prevention of cirrhosis of liver.

\subsection{Socio-Demographic Characteristics of Cirrhosis of Liver Patient}

Twenty interviews were conducted. Participants were in aged between 22 to 72 years old with an average age of $43.85( \pm 15.06)$ years. Most of them were male ( $\mathrm{n}$ $=14.70 \%)$, Muslim (90\%) and married (90\%). Majority of the participants were educated, and (20\%) participants were an alphabet. Above half of them 55\% were living in rural and below half of them $45 \%$ were living in the urban areas. Professionally, 7 (35\%) participants were service holders, 5 (25\%) were housewife and their average monthly income was $18550.00 \pm 10184.99$ BDT. Among all participants $65 \%$ were smoker and only $10 \%$ alcohol abuser. The average duration of suffering from the Cirrhosis of liver was $2.07 \pm 3.95$ years. And $45 \%$ patients reported that their treatment cost has been carried by their family members (Table 1).

Table 1. Distribution of socio-demographic characteristics of cirrhosis of liver patients (n $=20)$.

\begin{tabular}{|c|c|c|c|c|}
\hline Characteristics & Categories & Frequency (n) & Percentage (\%) & Mean \pm SD \\
\hline \multicolumn{5}{|l|}{ Age (years) } \\
\hline \multirow{4}{*}{ Mini $=22$ Maxi $=72$} & & & & $43.85 \pm 15.06$ \\
\hline & $<40$ & 7 & 35 & \\
\hline & $40-59$ & 10 & 50 & \\
\hline & $\geq 60$ & 3 & 15 & \\
\hline \multicolumn{5}{|l|}{ Gender } \\
\hline & Male & 14 & 70 & \\
\hline & Female & 6 & 30 & \\
\hline \multicolumn{5}{|l|}{ Religion } \\
\hline & Muslim & 18 & 90 & \\
\hline & Hindu & 2 & 10 & \\
\hline \multicolumn{5}{|l|}{ Marital status } \\
\hline & Single & 2 & 10 & \\
\hline & Married & 18 & 90 & \\
\hline
\end{tabular}




\section{Continued}

Education

$\begin{array}{lcc}\text { Analphabet } & 4 & 20 \\ \text { Primary school } & 5 & 25 \\ \text { Secondary } & 11 & 55\end{array}$

Place of residence

$\begin{array}{lcc}\text { Urban } & 9 & 45 \\ \text { Rural } & 11 & 55\end{array}$

Occupation

$\begin{array}{lll}\text { Housewife } & 5 & 25 \\ \text { Service } & 7 & 35 \\ \text { Farmer } & 3 & 15 \\ \text { Business } & 5 & 25\end{array}$

Income

Mini $=10,000$, Maxi $=50,000$

$\begin{array}{lcc}\geq 20,000 & 15 & 75 \\ <20,000 & 5 & 25\end{array}$

History of smoking

$\begin{array}{lll}\text { Yes } & 13 & 65 \\ \text { No } & 7 & 35\end{array}$

Alcohol consume

$\begin{array}{lcc}\text { Yes } & 2 & 10 \\ \text { No } & 18 & 90\end{array}$

Duration of suffering from cirrhosis of liver

$\begin{array}{lcc}<1 \text { year } & 11 & 55 \\ \geq 1 \text { year } & 9 & 45\end{array}$

Pay for treatment cost

$\begin{array}{lll}\text { Self } & 6 & 30 \\ \text { Family } & 9 & 45 \\ \text { Self and relatives } & 5 & 25\end{array}$

\subsection{Experiences of Cirrhosis of Liver Patient}

\subsubsection{Theme 1. Uncertainty about Disease and Its Causes}

All the participants were hospitalized patients with diagnosis of cirrhosis of liver. But most of them didn't know the name of disease and have no idea about their diseases. As patients mentioned:

"I have no idea about this disease." ( $P 2, P 3, P 4, P 5, P 6, P 7)$

"I cannot realize what the reason of this disease." $(P 1,2,15,16,17)$

Some participants simply mentioned that they had been suffering from liver problems as well as jaundice, hepatitis and virus. 
"I have been suffering from Jaundice, Hepatitis $B$ virus and abdominal disease for two months. I know that my liver has been enlarged." ( $P 15)$

Most of the patients didn't know the exact name of their disease. Participants either did not understand or missed key information regarding their diseases results, which ignited feeling of stress. They were often left feeling frustrated about the treatment and prognosis from the disease. As they mentioned that;

"This is a serious disease. Allah knows whether Pll be free from this disease or not. I am mentally depressed. I don't feel good in the hospital. It has been possible to stay here for my mother." (P19)

Only two patients knew the name of their disease "cirrhosis liver". They stated that

"I went to a doctor. He suggested me several tests. After evaluation the reports doctor informed me I am suffering from liver cirrhosis." $(P 18,19)$

It was difficult for the patients to identify the real cause of cirrhosis of liver disease. But patients mentioned some life style related factors would be etiologies/causes to develop their cirrhosis of liver, such as smoking habit, feeding outside, drinking water, constipation and also lack of awareness. Some patients mentioned that comorbidities would because of CL disease. In sharing the experience of causes of cirrhosis of liver patients expressed that:

"The main reason is smoking, lack of awareness, drinking water, environment, and unhygienic foods taking from hotel. Jaundice comes from constipation. Tasty salt is very harmful." (P13)

"I was fatty earlier. I have been suffering from diabetes due to fattiness since 2005. Diabetes Mellitus and smoking would be the causes of this disease." (P7)

A few of patients also have superstition about the causes of cirrhosis of liver disease.

"As I am businessman, it would be due to taking meals at irregular interval." $(P 8)$

“No, I can't say, I think it has been developed from gastric." (P14)

\subsubsection{Theme 2. Feeling Worse}

Patients had a wide range of self-reporting experiences about the symptoms or different physical problems related to cirrhosis of liver. Majority of the patients reported that they were suffering from abdominal swelling (ascites) that hampered their normal activities. Impaired taste in foods, long term constipation history, sometimes more dramatic acute gastrointestinal bleeding occurs with vomiting and stool. The most frequently reported symptoms were sleeping disturbances, abdominal pain, fever, burning sensation and others.

"Fluid accumulation into hands and legs, urine was yellow color. At first I thought it was for hot weather. My eyes were yellowish and had developed, high grade fever and sometimes blood came up from the nose..." (P5).

"I don't feel good, lack of sleep, losing weight, no taste in foods, sometimes black color stool, vomiting with blood." $(P 1)$

"I don't feel comfort, I have burning sensation in my body, can't do any work, 
can't forbear the heat of fire, can't take any oily food and can't take any food properly." (P16)

Majority of the participants reported limited mobility, weight loss due to changing dietary pattern and were encounter from different emotional feelings such as restlessness, sadness, frustration and fear of dying due to of physical and social limitation.

"I feel weak. I can't walk. If I could walk, diabetics would be under control. According to advice of doctor I take my meals. I try to take balanced food. No need to taste. There is mental pressure." (P6)

"I can't take my meals, losing weight, now I can't do any work. There is mental pressure. What happened and what will do?" $(P 1)$

A few of the participants also mentioned, they have no change on dietary habit, physical and spiritual activities, because of earlier stage of cirrhosis of liver.

"At home I say my prayers, but in the hospital I can't do so. I can sleep properly. I can do all works." $(P 7)$

\subsubsection{Theme 3. Living in Physical Impairment and Economic Crisis}

Despite, receiving satisfactory support from the family members, most of the patients had limitation on their social and recreational activities. They still experienced psychosocial problem such as feeling of loneliness because they didn't join with any social activities. Unemployment was important factor for every patient particularly young male. Because, most of the patients become dependent and burden for other family members. Because, majority of the patients were only earning member in their family.

"I live from hand to mouth. I have been unable to do any work for two months. What will do and take my sons? There was a cow, I sold it. Now there is nothing but homestead. If it is sold, where will go my family?" (P18)

"Hearing about this disease I am mentally weak. I have a good relation with my family members and the people of society but now I am detached from social activities. There is also financial crisis." (P5)

Besides, some of them were more worried about survival of their children without themselves; they expressed their feeling in this way;

"I have no fear of death. I am ready, but I have a little mental pressure with death, because I have two little children. Who will take care of them?" (P11)

Physical problems from cirrhosis of liver disease also greatly impact on the persons spiritual activities. Patients repeatedly reported that they were not performing their prayers perfectly.

"Life is boring. I can't move, oh sad! For disease I can't pray properly. I am praying on lying position in the bed." ( $P 1)$

\subsubsection{Theme 4. Coping with Disease}

Patients were worried to deal with the uncertainty of the situation and hoping for the best. An important issue was a deliberate cognitive and emotional distance to enable better coping. A positive mind set was a key strategy to minimize 
uncertainty.

Some people did not know what types of support were available to them due to lack of awareness and they struggle to articulate what support they would value most. More than half of the patients experienced different strategies to adapt and cope with illness related uncertainty.

"When there is pain, I try to control my pain keeping a piece of wet cloth on my abdomen and for headache my wife or my daughter do massage and caresses on the head." ( $P 18)$

When patients were very uncertain about disease and its future they were using self-convinced strategy, such as

"I satisfy myself mentally saying this Allah has given me this disease. Free from disease is the blessing of Allah, illness is also the blessing of Allah. I wish no one would suffer from this disease." (P19)

\subsubsection{Theme 5. Self-Actualization about Prevention of Cirrhosis of Liver} Majority of the patients suggested all people to avoid smoking, alcohol, using tobacco, increasing awareness, taking vaccination and avoiding outside foods to prevent this kinds of life threating disease and leading peaceful life. As the participants mentioned that:

"I forbid those children who are smoking. Betel leaves and tobacco should not be taken. If these are taken, it may be cancer. Liver also can damaged." (P18)

"Life threatening disease occurs from smoking. Should give up the habit of taking oil and spicy foods and taking well cooked food. Everybody should raise awareness. Health and fitness are two main parts of the life to leave the world peacefully..." $(P 13)$

Among all participants one patient advised to avoid marriage after diagnosing the disease and also advised to take vaccine and to maintain better personal lifestyle. As the participant expressed that

"At present, vaccine is available. My son get vaccinated, however unfortunately my daughter diagnosed as a case of HBsAg positive. The person who is diagnosed before marriage, hel she should not get married." (P8)

\section{Discussion}

The study sought to explore the lived experience of cirrhosis of liver patient. This chapter discussed in details about the cirrhosis of liver patient's socio-demographic characteristics and their lived experiences of the current study with relevant findings of the other study. Gribch, (2007) stated phenomenology is an approach to perceive the hidden meaning and the summary of an experience together. Max van Manen (1990) also marked that Phenomenology as a reply to one how orients to lived experience and the question the way to one experiences the world [29].

\section{Socio-demographic characteristics of cirrhosis of liver}

The current study found that the mean age of participants was $43.85 \pm 15.06$ years whereas study from [21] [30] reported mean age 47.44 \pm 14.41 and $58 \pm 11$ 
years. So it has been noticed that maximum people have been sufferings from cirrhosis of liver middle age than early and older age. Among all study participants most of being were male (14) cirrhotic patient that are the similar with others study including Bangladesh [2] [24] [30] [31]. Male and middle age are very much interrelated to develop cirrhosis of liver disease because this is the working group of people; they move to here and there have high chance to take outside foods and drinking water. On the other hand, female have little chance to receive treatment generally in this country. But others two study found that there were maximum of the patients were female [14] [26] it may due to higher education and awareness.

One of the study reported that $72.2 \%$ affected people had college degree [14] but another study mentioned that $67.5 \%$ of patients had at least high school degree [31]. In this study, 55\% patients have similar educational qualification. So, it is individuating that incognizance due to low educational factors may one of the causes of developing cirrhosis of liver. Almost equal numbers of participants were living in urban and rural areas of the current study.

The present study found that in Bangladesh, $65 \%$ patients were smoker but only $10 \%$ were alcoholic that was similar picture of other study in this country [2]. In this country, majority of the people had family bonding and were religious and introverted. So, they had few chance and interest to take alcohol. It is totally different from other country study findings that only $21.1 \%$ patients were non-alcoholic, so there alcohol related cirrhosis of liver rate was comparatively high.

It is overlooked from study of [2] duration of cirrhosis of liver ranged from 1 month to 15 years that was approximately similar with present study but their mean duration was 3.76 years that were some different from the present study.

Theme 1 . Uncertainty about disease and its causes

Though, prevalent of cirrhosis of liver rates and risk factors high including all liver diseases, limited knowledge among people about this disease throughout the world [32].

The present study identified that patients with cirrhosis of liver had already been affected but majority of them did not know their disease name and they have no knowledge about the disease severity, prognosis and also treatment facility. There may have some hidden factors such as-ignorance of the patient, communication gap between patient and health care providers (Doctors, Nurses and other health care personnel), misinterpretation or mis-understanding of professional language. Only two patients just mentioned their disease name "Cirrhosis of Liver". This is consistent with the literature reporting people were very much uncertain about hepatitis fibrosis who are inject drugs and living with hepatitis $C$ virus due to their limited knowledge [24] [26] [33] [34] [35]. On the other hand, one qualitative study was conducted among community people in Saudi Arabia, they were not patients but they had good knowledge regarding the meaning or definition of the Cirrhosis of liver. Because most of them were higher educated [14]. 
The main causes of cirrhosis of liver were smoking, food habits, HBV and $\mathrm{HCV}$ and but alcohol related cirrhotic patient was very few found in this study that was similar with other Bangladeshi study HBV related cirrhosis $49.22 \%$ and alcohol related only $4.02 \%$ [2]. Most of the Bangladeshi peoples were familial, socialize, religious and very much conservative, so there were very little chance of consuming alcohol. Study from Taiwan revealed totally different picture from the current study there were $78.9 \%$ cirrhotic patients were alcohol consumer and about eleven million adults estimated to drink regularly in UK [23] [36] it may relates to the median age, living in single and unemployment because they have chance to move freely here and there and low familial bonding.

Theme 2. Feeling Worse

A number of studies revealed that cirrhosis of liver patients were living with many symptoms. Majority of the patients experience abdominal pain, distended abdomen (acities), bleeding with faces and vomiting, respiratory distress, peripheral edema, anorexia and nausea and also psychological distress; incontinence of urine or oliguria, problems with mobility and balance and so on [25] [26] [30]. A quantitative study from South Korea reported that fatigue had highest score among all symptom experience followed by distended abdominal, peripheral edema, muscle cramps dry mouth and appearance change [31] that were more or less consistent to the current study. The patients experienced symptoms that had largely impacts on their normal daily activities, sleeping pattern, dietary pattern that cause of weight loss, psychological behavior and emotional feelings.

Theme 3. Living in Physical Impairment and Economical Crisis

Cirrhosis of liver disease largely impacts social activities and economic condition. In the current study, it was found that patients were isolated from social activities and unable to perform spiritual activities due to their limited physical mobility that were consistent with other study [37]. Since patients were affected with cirrhosis of liver in the median age and particularly men, this is the working age of life. As they were not able to work due to disease sufferings, so dependency on the family have increased that was mostly similar with other study [23] [38]. Majority of the patients were only earning member of the family. For this reason, cirrhosis of liver vastly impacted on the economic condition. Cirrhosis of liver had a severe negative impact on the financial and employment issues that are related to the daily lives and medical compliance [37] [39].

Theme 4. Coping with Disease

Majority of the patients described their hopes about accessing treatment, always they wanted to minimize or fight to cope with feeling of uncertainty and their disease symptoms. Patients experience some strategies such as abdominal pain. A wet cloth may reduce pain, massage therapy for headache. Positive mind set and self-convenience strategy are the major coping strategies in this study because most of the patients were Muslim and they were ready to accept the results from Allah, which technique was parallel with study of [26]. They had also familial and social support those were important factors to cope with emotional and psychological behavior. Other study reported that cirrhotic patients who 
were single lack a support system and they could not cope effectively with disease than those who were married [36] because their spouse influences them to receive treatment with a positive attitude. Participants adopted strategies to avoid stigmatizing condition by eschewing social contact and consultation about the physical condition [26].

Theme 5. Self-Actualization about Prevention of Cirrhosis of Liver

"Prevention is better than cure". However, most of the patients experienced some measures for all to prevent cirrhosis of liver from their own suffering experience. Patients reported that to eschew smoking, alcohol, tobacco using and taking outsides food and water, they also encouraged increasing public awareness, blood screening to detect viral infection, taking vaccination. Through increasing public awareness about this kind of life threating disease as well as cirrhosis of liver it may possible to maintain other preventive measures and free from disease. This findings is more or less consistent with the other one study though that study participants were clinicians, they also reported about increasing political awareness, clinicians education and improving funding [13] that's were very important issue to control and prevent cirrhosis of liver as well as liver cancer internationally.

One of the study regarding attitude toward testing, treatment and vaccination among women, they experienced there were some main barriers to receive treatment and vaccination because disease specific knowledge was very low, stigma and also treatment facility not accessible [35].

\section{Conclusions and Recommendation}

\subsection{Conclusion}

A phenomenological study was conducted among cirrhosis of liver patient to explore their lived experiences. The findings of the study may help the nurses to realize cirrhotic patient's miserable conditions and provide nursing care through proper nursing diagnosis. This study identifies that patients with cirrhosis of liver were uncertain about their disease understanding and occurring causes, prognosis and future of the disease. They were living with unpredictable sufferings physically, psychologically and also have a highly negative impact on socio-economic condition. Patients have experienced coping strategy with their sufferings. Majority of the patients also mentioned preventive measures for cirrhosis of liver especially taking vaccination and avoiding smoking and outside foods.

\subsection{Recommendation}

Further large scale study is in needed using advanced qualitative study design to explore the real life situation of the cirrhosis of liver patient including their fatigue and self-care behavior.

Patients were recruited in a single locality from specialist in-patient hepatology unit. It is necessary to collect data from different setting in Bangladesh. Their experiences may differ from other areas and hospital. 
Maximum patients with cirrhosis of liver were not interested to provide information due to their physical weakness and lack of awareness, so public awareness is needed to increase about the cirrhosis of liver through media e.g. television, radio, poster and also seminar and symposium in different places.

\section{Conflicts of Interest}

The authors declare no conflicts of interest regarding the publication of this paper.

\section{References}

[1] Almani, S.A., Memon, A.S., Memon, A.I., Shah, I., Rahpoto, Q. and Solangi, R. (2008) Cirrhosis of Liver: Etiological Factors, Complications and Prognosis. Journal of the Liaquat University of Medical and Health Sciences, 7, 61-66. https://doi.org/10.22442/jlumhs.08720145

[2] Das, D.C., Al Mahtab, M., Rahim, M.A., Malakar, D., Kabir, A. and Rahman, S. (2016) Hepatitis B Virus Remains the Leading Cause of Cirrhosis of Liver in Bangladesh. Bangladesh Medical Journal, 45, 164-166. https://doi.org/10.3329/bmj.v45i3.33137

[3] Safaei, A., Tavirani, M.R., Oskouei, A.A., Azodi, M.Z., Mohebbi, S.R. and Nikzamir, A.R. (2016) Protein-Protein Interaction Network Analysis of Cirrhosis Liver Disease. Gastroenterology and Hepatology from Bed to Bench, 9, 114.

[4] Zhang, R., Liu, Y., Zhu, J., Hu, M. and Wang, J. (2017) Effect of Individual Psychological Nursing Intervention on Quality of Life and Mental Health Status of Patients with Liver Cirrhosis. Biomedical Research, 28, 9994-9997.

[5] El Khoury, A.C., Vietri, J. and Prajapati, G. (2014) Health-Related Quality of Life in Patients with Hepatitis C Virus Infection in Brazil. Revista Panamericana de Salud Pública, 35, 200-206.

[6] Kimbell, B. and Murray, S.A. (2015) What Is the Patient Experience in Advanced Liver Disease? A Scoping Review of the Literature. BMJ Supportive \& Palliative Care, 5, 471-480. https://doi.org/10.1136/bmjspcare-2012-000435

[7] Flamm, S.L. (2017) Diagnosis of Cirrhosis and Evaluation of Hepatic Encephalopathy: Common Errors and Their Significance for the PCP. Journal of Family Practice, 66, S34-S39.

[8] Gill, J., Baiceanu, A., Clark, P.J., Langford, A., Latiff, J., Yang, P.M., Kanavos, P., et al. (2018) Insights into the Hepatocellular Carcinoma Patient Journey: Results of the First Global Quality of Life Survey. Future Oncology, 14, 1701-1710. https://doi.org/10.2217/fon-2017-0715

[9] Sarin, S.K., Kumar, M., Eslam, M., George, J., Al Mahtab, M., Akbar, S.M.F., Omata, M., et al. (2020) Liver Diseases in the Asia-Pacific Region: A Lancet Gastroenterology \& Hepatology Commission. The Lancet Gastroenterology \& Hepatology, 5, 167-228. https://doi.org/10.1016/S2468-1253(19)30342-5

[10] Shah, S.M.A., Mashia, S.A., Younus, M.F., Ghauri, A., Ejaz, R., Alshalabi, H., Umar, M., et al. (2015) Hepatic Cirrhosis-Disease Burden. Journal of Rawalpindi Medical College, 19, 17-20.

[11] Noor-E-Alam, S.M. (2018) Management of Hepatocellular Carcinoma: Bangladesh Perspective. Euroasian Journal of Hepato-Gastroenterology, 8, 52. https://doi.org/10.5005/jp-journals-10018-1258 
[12] Al Mahtab, M. (2017) Elimination of Hepatitis Viruses: Bangladesh Scenario. Euroasian Journal of Hepato-Gastroenterology, 7, 40. https://doi.org/10.5005/jp-journals-10018-1209

[13] Bridges, J.F., Gallego, G. and Blauvelt, B.M. (2011) Controlling Liver Cancer Internationally: A Qualitative Study of Clinicians' Perceptions of Current Public Policy Needs. Health Research Policy and Systems, 9, 32. https://doi.org/10.1186/1478-4505-9-32

[14] Al-Johani, J.J., Aljehani, S.M. and Alzahrani, G.S. (2018) Assessment of Knowledge about Liver Cirrhosis among Saudi Populationt. The Egyptian Journal of Hospital Medicine, 71, 2443-2446. https://doi.org/10.12816/0045639

[15] Ashraf, H., Alam, N.H., Rothermundt, C., Brooks, A., Bardhan, P., Hossain, L., Gyr, N., et al. (2010) Prevalence and Risk Factors of Hepatitis B and C Virus Infections in an Impoverished Urban Community in Dhaka, Bangladesh. BMC Infectious Diseases, 10, 208. https://doi.org/10.1186/1471-2334-10-208

[16] Hepatitis Australia (2014) Living with Cirrhosis a Guided for People with Hepatitis Related-Cirrhosis.

[17] Polis, S. and Fernandez, R. (2015) Impact of Physical and Psychological Factors on Health-Related Quality of Life in Adult Patients with Liver Cirrhosis: A Systematic Review Protocol. JBI Database of Systematic Reviews and Implementation Reports, 13, 39-51. https://doi.org/10.11124/jbisrir-2015-1987

[18] Ullah, F., Khan, S., Afridi, A.K. and ur Rahman, S. (2012) Frequency of Different Causes of Cirrhosis Liver in Local Population. Gomal Journal of Medical Sciences, 10, 178-181.

[19] Williams, J.G., Roberts, S.E., Ali, M.F., Cheung, W.Y., Cohen, D.R., Demery, G., Ip, B., et al. (2007) Gastroenterology Services in the UK. The Burden of Disease, and the Organisation and Delivery of Services for Gastrointestinal and Liver Disorders: A Review of the Evidence. Gut, 56, 1-113. https://doi.org/10.1136/gut.2006.117598

[20] Youssef, N.F., El Kassas, M., Farag, A. and Shepherd, A. (2017) Health-Related Quality of Life in Patients with Chronic Hepatitis C Receiving Sofosbuvir-Based Treatment, with and without Interferon: A Prospective Observational Study in Egypt. BMC Gastroenterology, 17, 18. https://doi.org/10.1186/s12876-017-0581-1

[21] Adhikari, S. (2018) Health Related Quality of Life of Patient with Chronic Liver Disease in a Tertiary Hospital, Kathmandu. International Journal of Health Sciences and Research, 8, 178-188.

[22] Rehm, J., Samokhvalov, A.V. and Shield, K.D. (2013) Global Burden of Alcoholic Liver Diseases. Journal of Hepatology, 59, 160-168.

https://doi.org/10.1016/j.jhep.2013.03.007

[23] Williams, R. (2006) Global Challenges in Liver Disease. Hepatology, 44, 521-526. https://doi.org/10.1002/hep.21347

[24] Goutzamanis, S., Doyle, J.S., Thompson, A., Dietze, P., Hellard, M. and Higgs, P. (2018) Experiences of Liver Health Related Uncertainty and Self-Reported Stress among People Who Inject Drugs Living with Hepatitis C Virus: A Qualitative Study. BMC Infectious Diseases, 18, 151. https://doi.org/10.1186/s12879-018-3057-1

[25] Youssef, N.F. (2013) Health-Related Quality of Life, Symptoms Experience and Perceived Social Support among Patients with Liver Cirrhosis: A Cross-Sectional Study in Egypt.

[26] Kimbell, B., Boyd, K., Kendall, M., Iredale, J. and Murray, S.A. (2015) Managing Uncertainty in Advanced Liver Disease: A Qualitative, Multiperspective, Serial In- 
terview Study. BMJ Open, 5, e009241.

https://doi.org/10.1136/bmjopen-2015-009241

[27] Rahman, S., Ahmed, M.F. and Alam, M.J. (2014) Distribution of Liver Disease in Bangladesh: A Cross-Country Study. Euroasian Journal of Hepato-Gastroenterology, 4, 25. https://doi.org/10.5005/jp-journals-10018-1092

[28] Streubert Speziale, H.J. and Rinaldi Carpenter, D. (2007) Qualitative Research in Nursing: Advancing the Humanistic Imperative. 4th Edition, Lippincott Williams \& Wilkins, Philadelphia.

[29] Kafle, N.P. (2011) Hermeneutic Phenomenological Research Method Simplified. Bodhi: An Interdisciplinary Journal, 5, 181-200.

https://doi.org/10.3126/bodhi.v5i1.8053

[30] Low, J., Davis, S., Vickerstaff, V., Greenslade, L., Hopkins, K., Langford, A., Jones, L., et al. (2017) Advanced Chronic Liver Disease in the Last Year of Life: A Mixed Methods Study to Understand How Care in a Specialist Liver Unit Could Be Improved. BMJ Open, 7, e016887. https://doi.org/10.1136/bmjopen-2017-016887

[31] Kim, S.H., Oh, E.G., Lee, W.H., Kim, O.S. and Han, K.H. (2006) Symptom Experience in Korean Patients with Liver Cirrhosis. Journal of Pain and Symptom Management, 31, 326-334. https://doi.org/10.1016/j.jpainsymman.2005.08.015

[32] Ly, K.N., Xing, J., Klevens, R.M., Jiles, R.B., Ward, J.W. and Holmberg, S.D. (2012) The Increasing Burden of Mortality from Viral Hepatitis in the United States between 1999 and 2007. Annals of Internal Medicine, 156, 271-278. https://doi.org/10.7326/0003-4819-156-4-201202210-00004

[33] Glacken, M., Kernohan, G. and Coates, V. (2001) Diagnosed with Hepatitis C: A Descriptive Exploratory Study. International Journal of Nursing Studies, 38, 107-116. https://doi.org/10.1016/S0020-7489(00)00046-8

[34] Khaw, F.M., Stobbart, L. and Murtagh, M.J. (2007) I Just Keep Thinking I Haven't Got It Because I'm Not Yellow: A Qualitative Study of the Factors That Influence the Uptake of Hepatitis C testing by Prisoners. BMC Public Health, 7, 98. https://doi.org/10.1186/1471-2458-7-98

[35] Lally, M.A., Montstream-Quas, S.A., Tanaka, S., Tedeschi, S.K. and Morrow, K.M. (2008) A Qualitative Study among Injection Drug Using Women in Rhode Island: Attitudes toward Testing, Treatment, and Vaccination for Hepatitis and HIV. AIDS Patient Care and STDs, 22, 53-64. https://doi.org/10.1089/apc.2006.0206

[36] Lin, W.J., Huang, H.M., Lee, B.O. and Sun, F.K. (2017) The Relationships between Uncertainty and Coping Behaviors of Patients with Liver Cirrhosis. International Journal of Nursing \& Clinical Practices, 4, 261. https://doi.org/10.15344/2394-4978/2017/261

[37] Lee, L.J.H., Chen, C.H., Yao, G., Chung, C.W., Sheu, J.C., Lee, P.H., Wang, J.D., et al. (2007) Quality of Life in Patients with Hepatocellular Carcinoma Received Surgical Resection. Journal of Surgical Oncology, 95, 34-39.

https://doi.org/10.1002/jso.20374

[38] Accreditation Council for Continuing Medical Education (ACCME) and Chronic Liver Disease Foundation (CLDF) (2013) The Multidimensional Burden of Hepatic Encephalopathy, Hepatology Center of Educational Expertise.

[39] Bajaj, J.S., Wade, J.B., Gibson, D.P., Heuman, D.M., Thacker, L.R., Sterling, R.K., Bell, D.E., et al. (2011) The Multi-Dimensional Burden of Cirrhosis and Hepatic Encephalopathy on Patients and Caregivers. The American Journal of Gastroenterology, 106, 1646. https://doi.org/10.1038/ajg.2011.157 